\title{
Survival Rate of Living Related Kidney Transplant Patients in Surabaya
}

Authors:

\section{Decsa Medika, Aditiawardana, Chandra Irwanadi, Djoko Santoso, Pranawa, Widodo Nephrology Division - Internal Medicine Department RSUD Dr. Soetomo - Universitas Airlangga Surabaya, Indonesia}

\section{Editor:}

Ginova Nainggolan

Received 7 April 2019, revised 1 July 2019, accepted 17 July 2019, published 1 August 2019

\begin{abstract}
Background The survival outcome of transplant patients have improved in the past three decades. The short and long term survival of grafts and patients are still being widely studied. Many factors affect the survival rate such as age, gender, diabetes mellitus, and immunosuppressive therapy.
\end{abstract}

Objective The study aimed to provide patients' survival rates 1,3 , and 5 years after transplant.

Methods The study used a descriptive approach to 67 kidney transplant patients undergoing outpatient treatment from 1996 to 2016. The data collected were analyzed using SPSS with the Kaplan-Meier curve to observe the survival rate.

Result: The survival rate of patients in 1, 3, and 5 years were $100 \%, 97 \%$, and $94 \%$ respectively. The survival rate in geriatric and non-geriatric patients in the first year post-transplantation was both $100 \%$, the third year post-transplantation survival rate was $100 \%$ and $94.7 \%$, and the five year post-transplantation survival rate were $100 \%$ and $89.5 \%$. The survival rate of patients receiving tacrolimus vs cyclosporine were both 100\% in the first year, $97.1 \%$ vs $97 \%$ in the third year, and $97.1 \%$ vs $90.9 \%$ in the fifth year after transplant.

Conclusion The survival rate of kidney transplant patients in 1, 3, and 5 years after transplant were $100 \%$, $97 \%$, and $94 \%$. Geriatric patients and patients who received tacrolimus have the tendency for a higher survival rate. Further study with a bigger sample and appropriate design is needed to determine the risk factors for kidney transplant patients' survival.

Keyword: kidney transplantation, survival rate

Corresponding author:

e-mail: aditiawardana@gmail.com (Aditiawardana A)

\section{BACKGROUND}

Chronic kidney disease (CKD) continues to be the main health problem in many countries. The global prevalence of CKD, especially stage $3-5$, reaches 10 $14 \%$ of the general population and over one-third of the geriatric population. ${ }^{1,2}$ The prevalence of end-stage kidney disease (ESKD) in the United States was 369 per million population in 2010 alone and continues to increase. The modalities of renal replacement therapy (RRT) widely available for ESKD patients are hemodialysis, continuous ambulatory peritoneal dialysis (CAPD), and kidney transplant. Kidney transplant is deemed as the ideal RRT for ESRD patients, for it tends to result in better outcomes for survival and quality of life. ${ }^{3,4}$

The survival rate is a crucial indicator to evaluate the benefit of therapy, especially in kidney transplant. ${ }^{5}$ Survival rate of living-related kidney donor recipients have increased significantly for the past 3 decades, in particular, the first-year survival rate. However, multiple studies have found the short term survival rate improvement is not followed by the long term survival rate. ${ }^{3}$ Factors affecting the survival rate of kidney transplant patients are mainly of three categories: host factor, kidney factor, and immunosuppressant factor. ${ }^{7}$ The most frequent causes of death in kidney transplant 
patients are cardiovascular disease (CVD), infection, and malignancy. ${ }^{4}$

This study aimed to describe the survival rate of living related kidney transplant patients after having a minimum of 3 months of outpatient treatment in 1, 3, and 5 years after transplantation in Surabaya. The study also aims to describe factors affecting the survival rates in said patients.

\section{METHODS}

\section{Subjects}

Secondary data were obtained from the medical records of all kidney transplant patients in the outpatient setting in Surabaya from 1996 to 2016 and have undergone treatment for a minimum of three months after transplant surgery.

\section{Data Collection}

The data collected consisted of patients' age, gender, the etiology of CKD and the use of calcineurin inhibitors.

\section{Statistical Analysis}

The data collected were analyzed using SPSS $16^{\text {th }}$ version. The data of patients' age was further divided into geriatric ( $\geq 60$ years old) and non-geriatric category ( $<60$ years old). The collected data regarding the etiology of CKD were categorized into diabetic and non-diabetic, and the use of calcineurin inhibitors was categorized based on the use of tacrolimus and cyclosporine.

\section{RESULTS}

Sixty-seven patients were found to be eligible for the study, consisting of 54 male patients $(80.6 \%)$ and 13 female patients (19.4\%). Subjects' characteristics were further described in Table 1.

The general survival outcome in the first year was $100 \%$, in the third year $96.9 \%$, and in the fifth year 94\%. Figure 1 shows the Kaplan Maier curve from this study. In the geriatric group, survival in 3 years and 5 years are both $100 \%$, whereas in the non-geriatric group the 3 and 5-year survival was $94.7 \%$ and $89.5 \%$ (Figure 2).
Table 1. Subjects' Characteristics

\begin{tabular}{ll}
\hline Characteristics & Total \\
\hline $\begin{array}{l}\text { Sample size } \\
\text { Age }\end{array}$ & 67 \\
$<\mathbf{6 0}$ y.o. & $38(56.7 \%)$ \\
$\geq \mathbf{6 0}$ y.o. & $29(43.3 \%)$ \\
Gender & \\
Male & $54(80.6 \%)$ \\
Female & $13(19.4 \%)$ \\
Etiology of CKD & \\
$\begin{array}{l}\text { Diabetic } \\
\text { Non-diabetic }\end{array}$ & $10(14.9 \%)$ \\
Calcineurin & In- \\
hibitor & \\
Tacrolimus & $34(50.1 \%)$ \\
Cyclosporine & $33(49.3 \%)$ \\
\hline
\end{tabular}

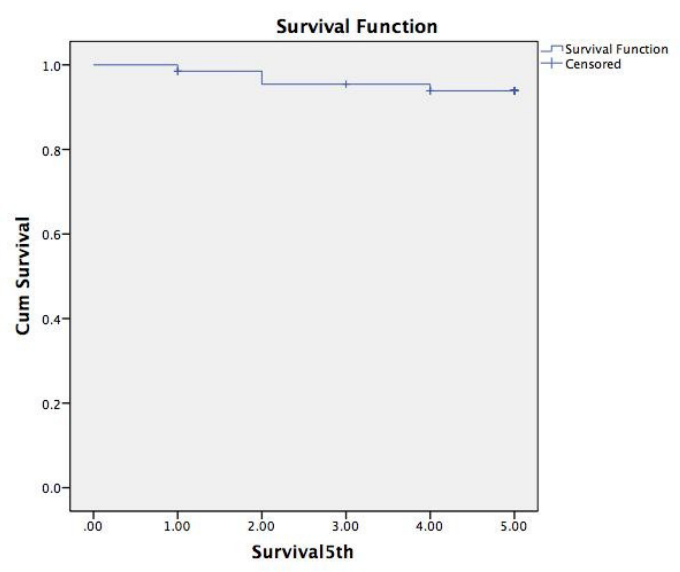

Figure 1. Kaplan Meier curve for 1, 3, and 5-year survival

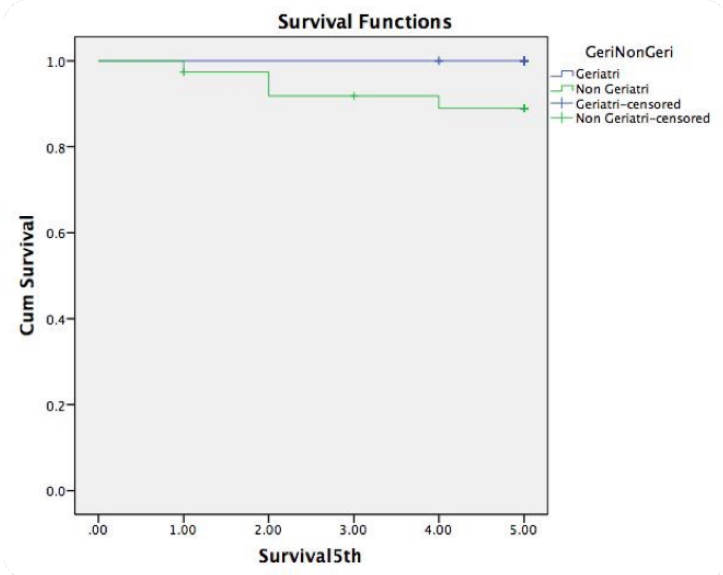

Figure 2. Kaplan Meier curve for 5-year survival of geriatric and non-geriatric patients 
Survival of transplant patients between male and $\mathrm{f}$ emale after 3 and 5 years were $100 \%$ vs $96.3 \%$ and $100 \%$ vs $92.6 \%$ respectively (Figure 3 ). Survival of kidney transplant patients divided into diabetics and non-diabetics group in the first year was $100 \%$, in the third year was $100 \%$ vs $96.5 \%$, and in the fifth year $100 \%$ vs $93 \%$ (Figure 4 ). The survival rate in patients receiving calcineurin inhibitors was categorized into those with tacrolimus and cyclosporine. Subjects in the tacrolimus group showed 100\% 1-year survival and $97.1 \%$ of 3 and 5-year survival. Subjects in cyclosporine showed 100\% 1-year survival, 97.1\% 3-year survival, and 90.9\% 5-year survival (Figure 5).

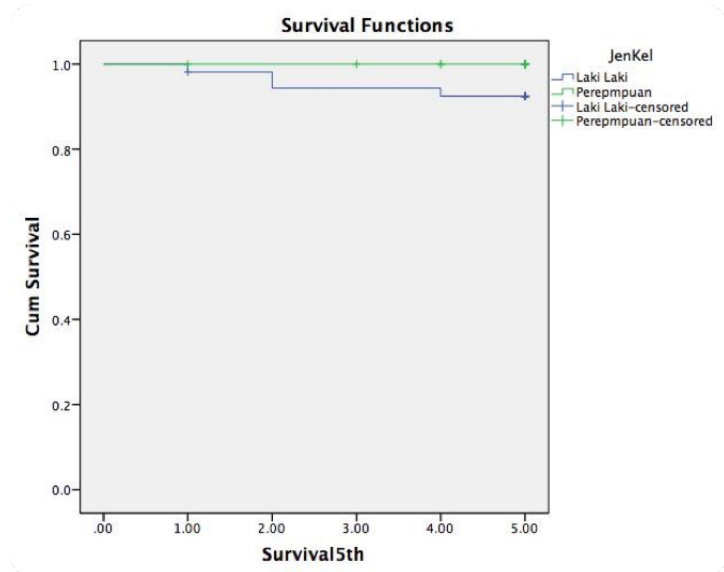

Figure 3. Kaplan Meier curve for 5 year-survival of male and female patients

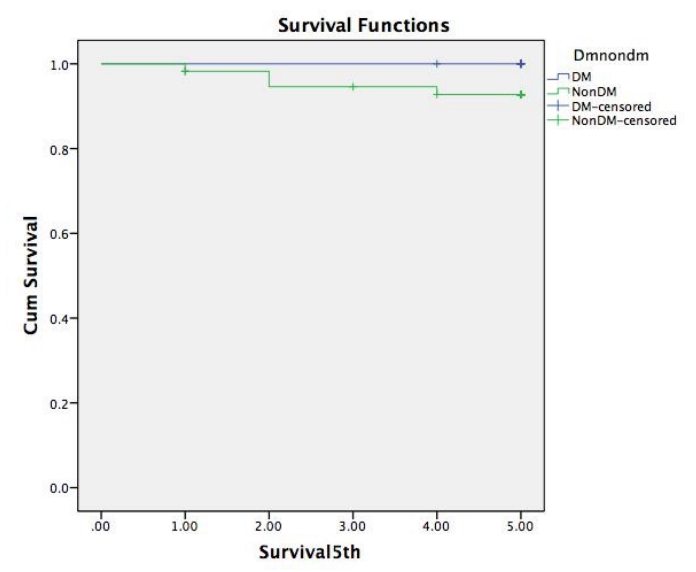

Figure 4. Kaplan Meier curve for 5 year-survival of diabetic and non-diabetic patients

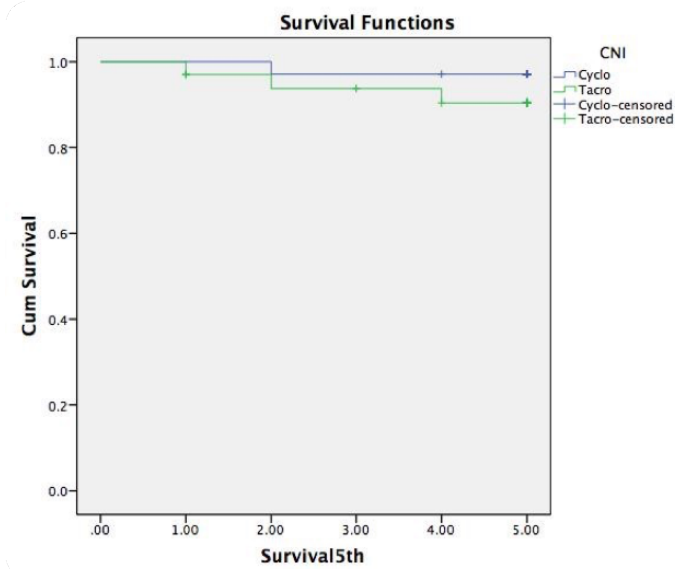

Figure 5. Kaplan Meier curve for 5 year-survival of patients with cyclosporin and tacrolimus

\section{DISCUSSION}

Most kidney transplant patients have a high survival rate, usually well above $95 \%$, supported by various researches with similar results. In 2010, the survival rate of kidney transplant patients in Iran for 1, 3, and 5 years after surgery were $98.5 \%, 96.4 \%$, and $92.5 \%{ }^{8}$ The high survival rate for kidney transplant patients is influenced by a multitude of factors such as the advancement of surgical procedures, minimum cold ischemia time, and the development of immunosuppressive therapies. ${ }^{9}$ The observation of kidney transplant survival rate is conducted after three months post-surgery, due to the high risk of complications in the said period of time.

In theory, geriatric patients have a higher tendency to develop complications such as cardiovascular disease and infection. Fabrizi et al studied the relationship between patients' age and the survival rate of kidney transplants and found second-year survival rate of non-geriatric patients were better than the geriatric patients (96\% vs 90\%). ${ }^{10}$ Another study also found the 5 -year survival rate of kidney transplant subjects in the non-geriatric category was $90 \%$ compared to the geriatric category survival of $82 \% .{ }^{11}$ In this study, the geriatric subjects were found to have higher 5-year survival outcomes $(94.7 \%$ vs $89.5 \%)$. The explanation for this result could be that geriatric patients have a lower chance of rejection due to a weaker immune system, leading to less immunosuppressive therapy. ${ }^{10}$ This is yet to be elucidated, but the latest study has found that acute graft rejection was found higher in non-geriatric patients, further supporting the role of the 
lower immune system in geriatric patients survival. ${ }^{11}$ Distribution of age between the subjects is also a confounding factor that needs to be considered.

The role of patients' gender in survival outcome in kidney transplant have been identified in past studies; male patients were at higher risk for cardiovascular diseases and female patients were found to be more compliant to immunosuppressive regimens and routine lab tests, leading to less graft rejection. ${ }^{3}$ In this study, the association between gender and survival rate cannot be assessed because of the uneven distribution of the subjects' gender.

The prevalence of cardiovascular diseases, posttransplant rejection, and infection in diabetic posttransplant patients have been reported to increase in 2004. However, the survival rate for diabetic posttransplant patients continues to improve over the years. $^{12}$ In this study, diabetic patients have $100 \%$ 1-year survival rate, 96.5\% 3-year survival rate, and 93\% 5-year survival rate. A study by Mamoun et al found diabetic post-transplant subjects have the survival rate of $80.4 \%$, lower in comparison to the survival rate of $88.7 \%$ in non-diabetic subjects. In the diabetic group, the infection rate was higher in the first 6 months post-surgery, but the overall 1-year survival rate was not affected with diabetes as long as patients have good glycemic control and receive cardioprotective drugs. ${ }^{12,13}$

Tacrolimus is a calcineurin inhibitor drug commonly used for immunosuppressive therapy in transplant patients, more preferred than cyclosporine. ${ }^{14,15}$ In this study, the survival rate of patients receiving tacrolimus in the $1^{\text {st }}, 3^{\text {rd }}$, and $5^{\text {th }}$ year after surgery were $100 \%$, $97 \%$, and $90.9 \%$. Meanwhile, the survival rate in the $1^{\text {st }}, 3^{\text {rd }}$, and $5^{\text {th }}$ year after surgery in the cyclosporine group were $100 \%, 97.1 \%$, and $97.1 \%$. In a study observing the 6-month survival, transplant patients receiving tacrolimus and cyclosporine have a survival rate of $98.5 \%$ and $99.3 \%$, respectively. Another study has shown the 1 and 5-year survival rate of patients receiving cyclosporine and tacrolimus did not differ, but the graft survival of the tacrolimus group is higher. ${ }^{16}$ However, the mortality outcome of patients receiving tacrolimus and cyclosporine can only truly be evaluated by a randomized clinical trial.

\section{STUDY LIMITATIONS}

This study is a single-center study with relatively small sample size. Being a descriptive study, this study also did not analyze the significant difference and association between variables. The subjects were also observed starting from three months after surgery, some have succeeded in surviving immediate complications of the procedure. The range of time of available data collected might also subject patients to the varying immunosuppressive regimen.

\section{CONCLUSION}

The survival rate of living-related kidney transplant patients in 1, 3, and 5 years after transplant were $100 \%$, $97 \%$, and $94 \%$. Factors associated to the higher survival rate were geriatric patients, female gender, diabetes, and the use of cyclosporine in the immunosuppressant therapy regimen. Further study with an appropriate design and bigger sample size is needed to determine the risk factors related to patient survival.

\section{REFERENCES}

1. Stengel B, Combe C, Jacquelinet C, Briancon S, Fouque D, Laville M, et al. The French Chronic Kidney Disease- Renal Epidemiology and Information Network cohort study. Nephrol Dial Transplant. 2014 Aug;29(8):1500-7. DOI: 10.1093/ndt/gft388.

2. Nahas M, Khwaja A. Chapter 79: Epidemiology, natural history, and pathophysiology of chronic kidney disease. In Johnson R, Feehally J, FLoege J, Tonelli M, et al. Comprehensive Clinical Nephrology. 5th ed. Amsterdam: Elsevier; 2015. p. 916-30.

3. Chen PD, Tsai MK, Lee CY, Yang CY, Hu $\mathrm{RH}$, Lee PH, et al. Gender differences in renal transplant graft survival. J Formos Med Assoc. 2013 Dec;112(12):783-8. DOI: 10.1016/j. jfma.2013.10.011.

4. Marques G, Romaozinho C, Santos L, Macario F, Alves R, Mota A. Kidney transplantation: which variables should be improved? Transplant Proc. 2015;47(4):914-9. DOI: 10.1016/j. transproceed.2015.03.023

5. Bicalho PR, Requião-Moura LR, Arruda ÉF, Chinen R, Mello L, Bertocchi APF, et al. LongTerm Outcomes among Kidney Transplant Recipients and after Graft Failure: A Single-Center Cohort Study in 
Brazil. BioMed Res Int. 2019;1-10. DOI: 10.1155/2019/7105084

6. Mirzaee M, Azmandia J, Zeraati H, Mahmoodi M, Mohammad K, Fazeli F, et al. Patient survival in renal allograft failure: a time-dependent analysis. Nephrourol Mon. 2014 Jan; 6(1): e13589. DOI: 10.5812/numonthly. 13589

7. Wavamunno MD, O'Connell PJ. Chapter 103: Chronic allograft injury. In Johnson R, Feehally J, FLoege J, Tonelli M, et al. Comprehensive Clinical Nephrology. 5th ed. Amsterdam: Elsevier; 2015. p 1200-10

8. Hassanzadeh J, Hashiani AA, Rajaeefard A, Salah A, Khedmati E, Kakaei F, et al. Long term survival of living donor renal transplants: A single center study. Indian J Nephrol. 2010;20(4):179-184. DOI: 10.4103/09714065.73439

9. Traynor C, Jenkinson A, Williams Y, Kelly PO, Hickey D, Denton M, et al. Twenty year survivors of kidney transplantation. Am J Transplant. 2012 Dec;12(12):3289-95. DOI: 10.1111/j.1600-6143.2012.04236.x

10. Fabrizi V, Winkelmayer WC, Klauser R, Kletzmayr J, Saemann MD, Steininger R, et al. Patient and graft survival in older kidney transplant recipients: does age matter? J Am Soc Nephrol. 2004;15(4): 1052-60.

11. Ozkul F, Erbis H, Yilmaz VT, Kocak H, Osmanoglu I, Dinckan A. Effect of Age on The Outcome of Renal Transplantation: A Single-Center Experience. Pak J Med Sci. 2016 Jul-Aug;32(4):827-30.

12. Keddis MT, Ters ME, Rodrigo E, Dean P, Wohlfahrtova M, Kudva YC, et al. Enhanced posttransplant management of patients with diabetes improves patient outcomes. Kidney Int. 2014 Sep;86(3):610-8. doi: 10.1038/ki.2014.70.

13. Maamoun HAH, Soliman AR, Fathy A, Elkhatib M, Shaheen N. Diabetes Mellitus as a predictor of patient and graft survival after kidney transplantation. Transplant Proc. 2013 Nov;45(9):3245-8. DOI: 10.1016/j.transproceed.2013.08.030.

14. Hamdy AF, Bakr MA, Ghoneim MA. Longterm efficacy and safety of a calcineurin inhibitor-free regimen in live-donor renal transplant recipients. J Am Soc Nephrol. 2008;19(6): 1225-32. DOI: 10.168/ASN.2007091001
15. Wissin KM, De Meyer V, \& Pipeleers L. Balancing Immunosuppressive Efficacy and Prevention of Posttransplant Diabetes-A Question of Timing and Patient Selection. Kidney Int Rep. 2018 Nov; 3(6): 1249-52. doi: 10.1016/j. ekir.2018.08.013

16. Patro KC, Ramakrishnan S, Kumar S, Roopa J, Dilip R. Comparison of patient and graft survival in tacrolimus versus cyclosporine-based immunosuppressive regimes in renal transplant recipients - Single-center experience from South India. Indian J Transplant. 2018;12:1658 